\title{
Framingham Risk Score Assessment in Subjects with Pre-diabetes and Diabetes: A Cross-Sectional Study in Korea
}

\begin{abstract}
Hyuk Sang Kwon', Kee Ho Song ${ }^{2}$, Jae Myung Yư ${ }^{3}$, Dong Sun Kim ${ }^{4}$, Ho Sang Shon ${ }^{5}$, Kyu Jeung Ahn ${ }^{6}$, Sung Hee Choi ${ }^{7}$, Seung Hyun $\mathrm{Ko}^{8}$, Won Kim ${ }^{9}$, Kyoung Hwa Lee ${ }^{9}$, Il Seong Nam-Goong ${ }^{10, *}$, Tae Sun Park ${ }^{11, *}$

${ }^{1}$ Division of Endocrinology and Metabolism, Department of Internal Medicine, Yeouido St. Mary's Hospital, College of Medicine, The Catholic University of Korea, Seoul; ${ }^{2}$ Department of Internal Medicine, Konkuk University Medical Center, Konkuk University School of Medicine, Seoul; ${ }^{3}$ Department of Internal Medicine, Hallym University Kangnam Sacred Heart Hospital, Hallym University College of Medicine, Seoul; ${ }^{4}$ Division of Endocrinology and Metabolism, Department of Internal Medicine, Hanyang University Hospital, Seoul; ${ }^{5}$ Department of Internal Medicine, Catholic University of Daegu School of Medicine, Daegu; ${ }^{6}$ Department of Endocrinology and Metabolism, Kyung Hee University School of Medicine, Seoul; ${ }^{7}$ Department of Internal Medicine, Seoul National University Bundang Hospital, Seongnam; ${ }^{8}$ Department of Endocrinology and Metabolism, Department of Internal Medicine, St. Vincent's Hospital, College of Medicine, The Catholic University of Korea, Suwon; ${ }^{9}$ Medical Department, Sanofi-Aventis Korea, Seoul; ${ }^{10}$ Department of Internal Medicine, Ulsan University Hospital, University of Ulsan College of Medicine, Ulsan; "Division of Endocrinology and Metabolism, Department of Internal Medicine, Jeonbuk National University Hospital, Jeonbuk National University Medical School, Jeonju, Korea
\end{abstract}

Background: This study aimed to evaluate cardiovascular risk in subjects with pre-diabetes and diabetes in Korea.

Methods: In this pan-Korean, non-interventional, cross-sectional study, data were collected from medical records of 10 hospitals between November 2013 and June 2014. Subjects (aged $\geq 40$ years) with medical records of dysglycemia and documentation of total cholesterol level, high-density lipoprotein cholesterol level, systolic blood pressure, and smoking status in the past 6 months were included. The primary endpoint was to determine the Framingham risk score (FRS). The relationships between FRS and cardiovascular risk factors, glycated hemoglobin, and insulin usage were determined by multiple linear regression analyses.

Results: Data from 1,537 subjects with pre-diabetes $(n=1,025)$ and diabetes $(n=512)$ were analyzed. The mean FRS (mean \pm standard deviation) in subjects with pre-diabetes/diabetes was $13.72 \pm 8.77$. FRS was higher in subjects with diabetes than pre-diabetes $(P<0.001)$. FRS in men with pre-diabetes was comparable to that in women with diabetes (13.80 \pm 7.37 vs. 13.35 \pm 7.13$)$. FRS was elevated in subjects who consumed alcohol (2.66, $P=0.033)$ and with obesity-class II $(6.10, P=0.015)$ among subjects with diabetes $(n=199)$, and was elevated in patients with left ventricular hypertrophy $(11.10, P=0.005)$, those who consumed alcohol $(3.06, P=0.000)$, were pre-obese $(3.21, P=0.002)$, or were obesity-class I $(2.89, P=0.002)$ among subjects with pre-diabetes $(n=306)$ in comparison to subjects without these coexisting risk factors.

Conclusion: Overall, Korean subjects with pre-diabetes and diabetes have an increased cardiovascular risk, which is significantly higher in those subjects with diabetes than with pre-diabetes. The present data can be used to develop measures to prevent and manage cardiovascular complications in Koreans with impaired glucose metabolism.

Key words: Cardiovascular diseases, Diabetes mellitus, Risk assessment
Received December 29, 2020

Reviewed March 15, 2021

Accepted April 23, 2021

*Corresponding author II Seong Nam-Goong

(iD) https://orcid.org/0000-0002-0492-0467

Department of Internal Medicine, Ulsan University Hospital, University of Ulsan College of Medicine, 877

Bangeojinsunhwan-doro, Dong-gu, Ulsan 44033, Korea

Tel: +82-52-250-7000

Fax: +82-52-250-8085

E-mail: isnamgoong@naver.com

${ }^{*}$ Co-Corresponding author

Tae Sun Park

https://orcid.org/0000-0001-7216-8468

Division of Endocrinology and Metabolism, Department of Internal Medicine, Jeonbuk National University Hospital, Jeonbuk National University Medical School, 20 Geonji-ro,

Deokjin-gu, Jeonju 54907, Korea

Tel: +82-63-250-1794

Fax: +82-63-270-3053

E-mail: pts@chonbuk.ac.kr

The first two authors contributed equally to this study. 


\section{INTRODUCTION}

In the last few decades, there has been a global increase in the prevalence of pre-diabetes and diabetes. ${ }^{1}$ In 2019, the worldwide prevalence of pre-diabetes among adults aged 20-79 years was $7.5 \%$ while that of diabetes was $9.3 \%$; these values have been projected to increase to $8.6 \%$ and $10.9 \%$, respectively, by $2045 .{ }^{1}$ Contribution of the Western Pacific region to the total global diabetes disease burden is approximately $35 \% .{ }^{1}$ Among countries in the Western Pacific region, the prevalence of diabetes in Korea increased from $12.4 \%$ in 2011 to $14.4 \%$ in 2016 and was higher in men $(15.8 \%)$ than in women $(13.0 \%){ }^{2}$ This increase was attributed to an aging population, westernized lifestyle, and other socioeconomic factors. ${ }^{3}$

Complications due to diabetes are associated with increased medical costs and reduced life expectancy. Cardiovascular disease (CVD) is the leading cause of morbidity and mortality in subjects with diabetes, and the risk of developing CVD is almost double that in individuals with diabetes compared to those without. ${ }^{1} \mathrm{CVD}$ is known to be associated with fasting plasma glucose (FPG); postprandial plasma glucose (PPG) is also an important determinant of CVD burden. ${ }^{46}$ Pre-diabetes increases the risk of CVD and all-cause mortality, and the risk appears to be present in subjects with an FPG as low as $100 \mathrm{mg} / \mathrm{dL}$ and glycated hemoglobin (HbAlc) of 5.7\%.7

International guidelines established by the American Diabetes Association and the European Association for the Study of Diabetes recommend a reduction in diabetes complications and CVD risk as the primary goal in the management of diabetes. ${ }^{8}$ In agreement with the international guidelines, the Korean Diabetes Association also emphasizes the evaluation and prevention of CVD while managing diabetes. ${ }^{9}$ Cardiovascular $(\mathrm{CV})$ risk should be assessed quantitatively to prevent and effectively manage CV complications in subjects with diabetes. Various algorithms have been devised for $\mathrm{CV}$ risk assessment, but their suitability for assessing risk in subjects with diabetes is unclear. ${ }^{10-13}$ The Framingham risk score (FRS) is one of the most useful CV risk calculators used globally in clinical practice to identify and treat high-risk populations as well as to communicate risk effectively. ${ }^{14,15}$

In Korea, the prevalence of pre-diabetes and diabetes is increasing, but information on associated CV risk is limited. In view of this, the OCARINA (a cross-sectional study to evaluate cardiovascular risk in prediabetic and diabetic patients) study was undertaken to investigate the relationship between FRS and CV risk factors (myocardial infarction $[\mathrm{MI}]$, stroke, history of $\mathrm{CV}$ revascularization, history of angina, left ventricular hypertrophy [LVH], coronary artery stenosis $>50 \%$, and carotid stenosis $>50 \%$ ) in subjects with pre-diabetes and diabetes in Korea.

\section{METHODS}

\section{Study design}

OCARINA was a pan-Korea, multicenter, non-interventional, cross-sectional study conducted in compliance with good epidemiologic practice. ${ }^{16}$ Physicians from 10 general hospitals in Korea, who managed and treated subjects with diabetes based on health system and expertise, participated in the study as investigators. The study period was from November 2013 to June 2014.

\section{Study population}

Subjects with pre-diabetes or diabetes aged $\geq 40$ years who visited outpatient departments at the ten medical institutions during the participating physicians' duty schedules were enrolled based on the availability of their case records. Type 2 diabetes mellitus (T2DM) was diagnosed based on plasma glucose (PG), FPG of $\geq 126 \mathrm{mg} / \mathrm{dL}$ or 2-hour PG of $\geq 200 \mathrm{mg} / \mathrm{dL}$ during a 75 -g oral glucose tolerance test (OGTT), or HbAlc level $\geq 6.5 \% .^{17-19}$ Pre-diabetes was diagnosed based on the presence of impaired fasting glucose (IFG) with FPG ranging from 100 to $125 \mathrm{mg} / \mathrm{dL}$ and/or impaired glucose tolerance with a 2-hour PG of 140 to $199 \mathrm{mg} / \mathrm{dL}$ during a 75-g OGTT, and/or HbAlc of $5.7 \%$ to $6.4 \%{ }^{17-19}$ Subjects with documented total cholesterol (TC) and high-density lipoprotein cholesterol (HDL-C) values, systolic blood pressure (SBP), and smoking status within the previous 6 months were included in the study. Subjects that were receiving any investigational drug; those with a history of MI, stroke, or major surgery; or those with a reported use of systemic glucocorticoids for a week within the 3 months preceding enrollment were excluded from the study.

\section{Data collection and verification}

Data from medical records were entered in electronic case report 
forms. Data included demographics, pharmacotherapy in the previous 6 months, record of CV risk factors, FPG, PPG, HbAlc, TC, HDL-C, antihyperlipidemic therapy, SBP, diastolic blood pressure (DBP), antihypertensive therapy, and smoking status.

\section{Study endpoints}

The primary endpoint of the study was to determine the FRS. Framingham equations for general $\mathrm{CV}$ risk were used to calculate the $\mathrm{CV}$ risk for the FRS using an online calculator (https://framinghamheartstudy.org/fhs-risk-functions/cardiovascular-disease-10-yearrisk/). Secondary endpoints included the percentage of subjects with high CV risk, the relationship between FRS and $\mathrm{HbAlc}$ level and insulin usage, and the relationship between high CV risk and $\mathrm{HbAlc} \mathrm{level} \mathrm{and} \mathrm{insulin} \mathrm{usage.}$

High CV risk in subjects was defined as having at least one of the following underlying CV risk factors: MI, history of stroke, prior revascularization, history of angina, urine albumin creatinine ratio (UACR) $>30 \mu \mathrm{g} / \mathrm{mg}$, history of $\mathrm{LVH}$, or stenosis of the coronary arteries.

\section{Statistical analysis}

Data collected from subjects were analyzed using descriptive statistics. Qualitative data were summarized as frequencies and percentages, while quantitative data were summarized using descriptive statistics (mean, standard deviation [SD], median, and range). Multiple linear regression was performed to investigate the relationship between FRS and CV risk factors, as well as FRS according to $\mathrm{HbAlc}$ level and insulin use. The association between presence of $\mathrm{CV}$ risk factors and $\mathrm{HbAlc}$ level and insulin usage was assessed by multiple logistic regression analysis. SAS versions 9.2 or higher (SAS Institute Inc., Cary, NC, USA) were used to perform all analyses.

\section{Ethical considerations}

This non-interventional, retrospective study protocol was approved by local ethics review committees with informed consent form exemption. Institutional review board approval numbers from the 10 hospitals that participated in this study are as follows: Konkuk University Medical Center (KUH1010518), Gangdong Kyung Hee University Hospital (2013-0077), Ulsan University Hospital (2013096), Chonbuk National University Hospital (CUH 2013-10-021), Seoul
National University Bundang Hospital (B-1310/222-112), Daegu Catholic University Hospital (CR-13-085-L), The Catholic University of Korea, Yeouido St. Mary's Hospital (XC13RSMI0125S), The Catholic University of Korea, St. Vincent's Hospital (XC13RSMI0125V), Hallym University Kangnam Sacred Heart Hospital (2013-11-91), and Hanyang University Hospital (HYUH 2013-11-015).

\section{RESULTS}

\section{Population demographics and clinical characteristics}

Out of 1,540 subjects screened, data from 1,537 subjects were included in the analysis; one subject was excluded because his/her medical record did not confirm dysglycemia at enrollment, and two other subjects were excluded as baseline data (TC, HDL-C, SBP, and smoking status) within 6 months before enrollment were missing.

About one-third (33\%, 512/1,537) of analyzed subjects had diabetes, while the remainder $(n=1,025)$ had pre-diabetes. More than half $(60.0 \%, 922 / 1,537)$ of the subjects were men; the mean \pm SD age and body mass index of the study subjects was $56.2 \pm 8.8$ years and $24.9 \pm 3.2 \mathrm{~kg} / \mathrm{m}^{2}$, respectively. The Mean \pm SD of SBP and DBP were $125.5 \pm 14.2 \mathrm{mmHg}$ and $75.7 \pm 9.6 \mathrm{mmHg}$, respectively. About one-fifth $(19.5 \%, 299 / 1,537)$ of subjects were active smokers. Fewer than half $(45.8 \%, 522 / 1,139)$ of subjects were alcohol consumers. The proportion of subjects who received antihypertensive and antihyperlipidemic therapy was $34.1 \%(430 / 1,261)$ and $49.7 \%$ $(573 / 1,154)$, respectively (Table 1$)$.

\section{FRS in subjects with diabetes and pre-diabetes}

In subjects whose records had all the data required for calculation of FRS ( $n=1,261)$, the mean \pm SD FRS was $13.72 \pm 8.77$ (Fig. 1). Through assumption of either "yes" or "no" when data for the parameter "treatment with antihypertensive drugs" was unavailable, the FRS score was $13.88 \pm 8.71$ and $13.30 \pm 8.66$, respectively (Supplementary Table 1 ).

Subjects with diabetes had a higher FRS $(18.99 \pm 8.79)$ than those with pre-diabetes $(10.74 \pm 7.23)(P<0.001)$ (Fig. 1). FRS in men with pre-diabetes was comparable to that in women with diabetes (13.80 \pm 7.37 and $13.35 \pm 7.13$, respectively) (Fig. 2). 
Table 1. Demographics of the study subjects

\begin{tabular}{|c|c|c|c|c|}
\hline Variable & $\begin{array}{l}\text { Diabetes } \\
(n=512)\end{array}$ & $\begin{array}{c}\text { Pre-diabetes } \\
(n=1,025)\end{array}$ & $\begin{array}{c}\text { Total } \\
(n=1,537)\end{array}$ & $P$ \\
\hline \multicolumn{5}{|l|}{ Anthropometrics } \\
\hline Age (yr) & $57.2 \pm 9.1$ & $55.7 \pm 8.6$ & $56.2 \pm 8.8$ & $0.001^{*}$ \\
\hline \multicolumn{5}{|l|}{ Sex } \\
\hline Male & $314(61.3)$ & $608(59.3)$ & $922(60.0)$ & $0.448^{\dagger}$ \\
\hline Female & $198(38.7)$ & $417(40.7)$ & $615(40.0)$ & $0.448^{\dagger}$ \\
\hline Height (cm) & $163.7 \pm 8.4$ & $163.2 \pm 9.1$ & $163.4 \pm 8.9$ & $0.369^{*}$ \\
\hline Weight (kg) & $68.4 \pm 11.6$ & $67.2 \pm 11.7$ & $67.6 \pm 11.7$ & $0.115^{*}$ \\
\hline $\mathrm{BMI}\left(\mathrm{kg} / \mathrm{m}^{2}\right)$ & $25.2 \pm 3.4$ & $24.7 \pm 3.1$ & $24.9 \pm 3.2$ & $0.012^{*}$ \\
\hline Waist circumference $(\mathrm{cm})$ & $88.2 \pm 10.1$ & $83.4 \pm 9.3$ & $84.4 \pm 9.6$ & $<0.001^{*}$ \\
\hline $\mathrm{SBP}(\mathrm{mmHg})$ & $126.6 \pm 3.6$ & $125.0 \pm 14.5$ & $125.5 \pm 14.2$ & $0.037^{*}$ \\
\hline $\mathrm{DBP}(\mathrm{mmHg})$ & $75.6 \pm 9.4$ & $75.7 \pm 9.6$ & $75.7 \pm 9.6$ & $0.848^{*}$ \\
\hline \multicolumn{5}{|l|}{ Lifestyle practice } \\
\hline \multicolumn{5}{|l|}{ Smoking } \\
\hline Yes & $117(22.9)$ & $182(17.8)$ & $299(19.5)$ & $0.017^{\dagger}$ \\
\hline \multicolumn{5}{|c|}{ Alcohol consumption $(n=1,139)$} \\
\hline Yes & $150(44.4)$ & $372(46.4)$ & $522(45.8)$ & $<0.001^{\dagger}$ \\
\hline \multicolumn{5}{|l|}{ Exercise $(n=854)$} \\
\hline Yes & $115(51.8)$ & 377 (59.7) & $492(57.6)$ & $0.042^{\dagger}$ \\
\hline \multicolumn{5}{|l|}{ Current pharmacotherapy } \\
\hline \multicolumn{5}{|l|}{ Antihypertensive $(\mathrm{n}=1,261)$} \\
\hline Yes & $203(44.5)$ & $227(28.2)$ & $430(34.1)$ & $<0.001^{\dagger}$ \\
\hline \multicolumn{5}{|c|}{ Antihyperlipidemic $(n=1,154)$} \\
\hline Yes & $230(59.4)$ & $343(44.7)$ & $573(49.7)$ & $<0.001^{\dagger}$ \\
\hline
\end{tabular}

Values are presented as mean \pm standard deviation or number (\%). Denominator of the percentage is the number of subjects. Subjects with unknown information were not included: height: 563 subjects, weight: 375 subjects, alcohol consumption: 398 subjects, exercise status: 683 subjects, treatment with antihypertensive drugs: 276 subjects, and treatment with antihyperlipidemic drugs: 341 subjects (missing data in 42 subjects).

${ }^{*}$ t-test; ${ }^{\dagger}$ Chi-square test.

BMI, body mass index; SBP, systolic blood pressure; DBP, diastolic blood pressure.

\section{Subjects with high CV risk and associated FRS}

Among 132 subjects whose high-risk status could be ascertained, 81 (61.4\%; 95\% confidence interval [CI], 53.06-69.67) presented with at least one risk factor (thus falling in the high CV risk category). The most prevalent CV risk factor was angina, reported in 28 subjects $(2.72 \%)$, followed by stroke $(n=17,1.66 \%)$, ankle-brachial index $<0.9(n=15,7.77 \%)$, UACR $>30 \mu \mathrm{g} / \mathrm{mg}(\mathrm{n}=10,3.46 \%)$, $\mathrm{LVH}(\mathrm{n}=9,1.02 \%), \mathrm{MI}(\mathrm{n}=6,0.58 \%)$, prior revascularization $(\mathrm{n}=6$, $0.60 \%)$, and $\geq 50 \%$ stenosis of coronary arteries $(n=2,0.22 \%)$. No subject had $\geq 50 \%$ stenosis of the lower extremity or carotid arteries.

In subjects with high CV risk (presence of $\geq 1 \mathrm{CV}$ risk factors), the mean \pm SD of FRS was $17.86 \pm 8.86$; in comparison, the FRS in those without any coexistent $\mathrm{CV}$ risk factor was $14.58 \pm 8.54(P=$

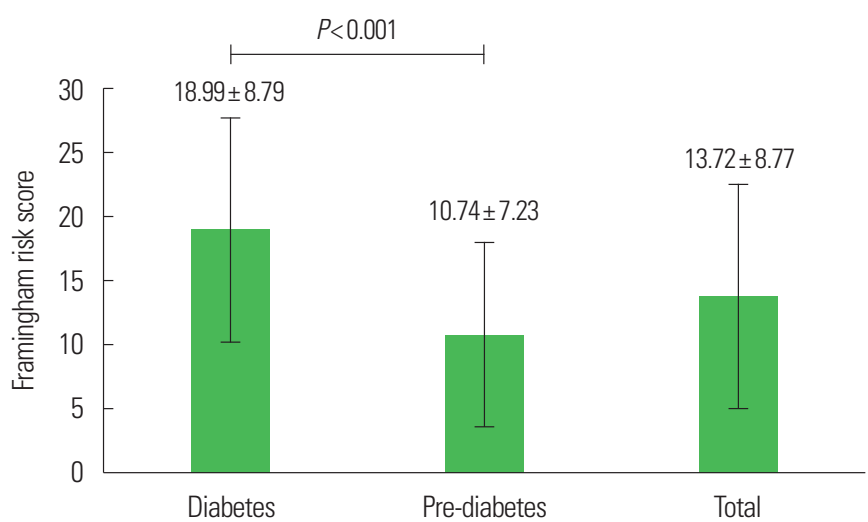

Figure 1. Comparison of Framingham risk score between diabetes and pre-diabetes.Values are presented as mean \pm standard deviation. Framingham risk score comparison between diabetes vs. pre-diabetes by t-test.

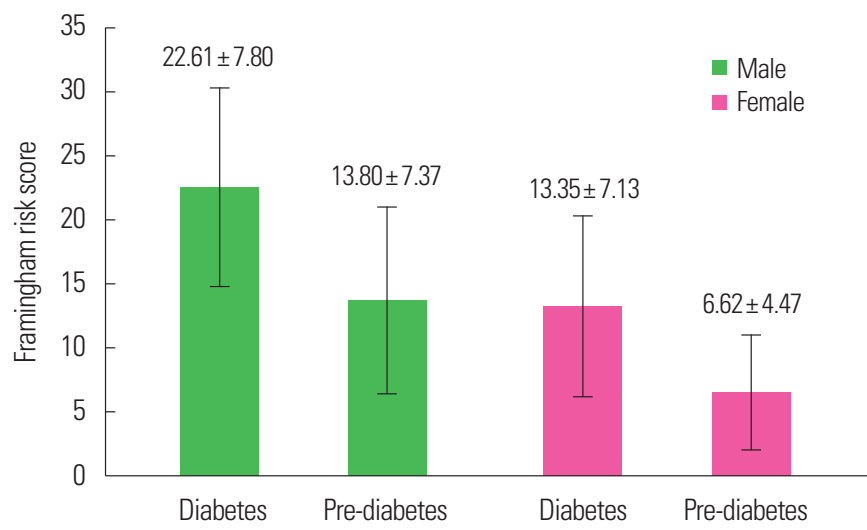

Figure 2. Comparison of Framingham risk score within pre-diabetes and diabetes populations by sex. Values are presented as mean \pm standard deviation. Sex comparisons within pre-diabetes and diabetes population by analysis of variance. Multiple comparisons by Duncan's test. Male diabetes $>$ male pre-diabetes $=$ female diabetes $>$ female pre-diabetes $(P<0.001)$.

0.048). FRS was higher in subjects with stroke $(\Delta=4.49, P=0.032)$, angina $(\Delta=6.58, P=0.000), \operatorname{LVH}(\Delta=9.21, P=0.003)$, alcohol consumption $(\Delta=3.66, P<0.001)$, higher BMI $(\Delta=0.3$ [underweight vs. normal], $\Delta=2.14$ [pre-obesity vs. normal], and $\Delta=3.14$ [obesity vs. normal]; $P<0.001)$, and higher $\operatorname{HbAlc}(\Delta=3.48$ [tertile 2 vs. 1 ],$\Delta=6.83$ [tertile 3 vs. 1 ]; $P<0.001)$ than in those without these coexisting risk factors. FRS was substantially elevated in patients with angina $(\Delta=4.57 ; P=0.019)$ and those who consumed alcohol $(\Delta=3.96, P=0.000)$ among subjects with diabetes and in those with stroke $(\Delta=5.1, P=0.031), \mathrm{LVH}(\Delta=11.76, P=0.005)$, alcohol consumption $(\Delta=3.62, P<0.001)$, higher BMI $(\Delta=-4.19$ [underweight vs. normal], $\Delta=1.74$ [pre-obesity vs. normal], and $\Delta=2.06$ [obesity vs. normal]; $P=0.000)$, and higher HbAlc $(\Delta=$ 
Table 2. Effect of cardiovascular risk factors on the Framingham risk score

\begin{tabular}{|c|c|c|}
\hline Variable & Parameter estimate (SE) & $P^{*}$ \\
\hline \multicolumn{3}{|l|}{ Overall $(n=469)^{\dagger}$} \\
\hline Stroke presence (vs. none) & $3.28(3.11)$ & 0.291 \\
\hline Angina presence (vs. none) & $1.65(3.10)$ & 0.594 \\
\hline LVH presence (vs. none) & $10.75(3.34)$ & 0.001 \\
\hline Alcohol consumption presence (vs. none) & $3.22(0.75)$ & $<0.001$ \\
\hline HbA1c tertile 2 (vs. tertile 1) & $3.31(0.93)$ & $<0.001$ \\
\hline HbA1c tertile 3 (vs. tertile 1) & $7.22(0.88)$ & $<0.001$ \\
\hline BMl underweight (vs. normal weight) & $9.02(4.05)$ & 0.026 \\
\hline BMI pre-obesity (vs. normal weight) & $2.92(1.04)$ & 0.005 \\
\hline BMI obesity-class I (vs. normal weight) & $3.21(0.90)$ & $<0.001$ \\
\hline BMI obesity-class II (vs. normal weight) & $4.00(1.80)$ & 0.027 \\
\hline BMI obesity-class III (vs. normal weight) & $1.28(4.05)$ & 0.751 \\
\hline \multicolumn{3}{|l|}{ Diabetes $(n=199)^{\dagger}$} \\
\hline Angina presence (vs. none) & $4.98(2.96)$ & 0.094 \\
\hline Alcohol consumption presence (vs. none) & $2.66(1.24)$ & 0.033 \\
\hline BMl underweight (vs. normal weight) & $3.49(4.49)$ & 0.437 \\
\hline BMI pre-obesity (vs. normal weight) & $1.93(1.80)$ & 0.285 \\
\hline BMI obesity-class I (vs. normal weight) & $2.70(1.56)$ & 0.085 \\
\hline BMI obesity-class II (vs. normal weight) & $6.10(2.49)$ & 0.015 \\
\hline BMI obesity-class III (vs. normal weight) & $0.91(5.12)$ & 0.859 \\
\hline \multicolumn{3}{|l|}{ Pre-diabetes $(n=306)^{\dagger}$} \\
\hline Stroke presence (vs. none) & $4.40(2.82)$ & 0.119 \\
\hline LVH presence (vs. none) & $11.10(3.94)$ & 0.005 \\
\hline Alcohol consumption presence (vs. none) & $3.06(0.78)$ & $<0.001$ \\
\hline HbA1c tertile 2 (vs. tertile 1) & $1.02(0.90)$ & 0.257 \\
\hline HbA1c tertile 3 (vs. tertile 1) & $1.86(0.96)$ & 0.054 \\
\hline BMl underweight (vs. normal weight) & NA & NA \\
\hline BMl pre-obesity (vs. normal weight) & $3.21(1.05)$ & 0.002 \\
\hline BMI obesity-class I (vs. normal weight) & $2.89(0.90)$ & 0.002 \\
\hline BMI obesity-class II (vs. normal weight) & $-0.11(2.11)$ & 0.958 \\
\hline BMI obesity-class III (vs. normal weight) & $3.65(4.71)$ & 0.439 \\
\hline
\end{tabular}

$\mathrm{HbA} 1 \mathrm{c}$ was subdivided into tertiles: $\mathrm{HbA} 1 \mathrm{c} \leq 5.9 \%$ (tertile 1 ), $>5.9 \%$ to $\leq 6.3 \%$ (tertile 2), and $>6.3 \%$ (tertile 3 ) for the overall population, $\mathrm{HbA1c} \leq 6.4 \%$ (tertile 1 ), $>6.4 \%$ to $\leq 7.0 \%$ (tertile 2), and $>7.0 \%$ (tertile 3 ) for the diabetes population; and $\mathrm{HbA} 1 \mathrm{C} \leq 5.7 \%$ (tertile 1), $>5.7 \%$ to $\leq 6.0 \%$ (tertile 2), and $>6.0 \%$ (tertile 3 ) for the pre-diabetes population; Underweight: $\mathrm{BMl}<18.5 \mathrm{~kg} / \mathrm{m}^{2}$, normal weight: BMl $18.5-22.9 \mathrm{~kg} / \mathrm{m}^{2}$, pre-obesity: BMI 23.0-24.9 kg/m², obesity-class I: BMI 25.0-29.9 kg/m², obesity-class II: BMI $30.0-34.9 \mathrm{~kg} / \mathrm{m}^{2}$, and obesity-class III: BMl $\geq 35 \mathrm{~kg} / \mathrm{m}^{2}$.

* Multivariable analysis of the relationship between risk factors and the Framingham risk score (multiple linear regression); ${ }^{\dagger}$ Number of observations with missing values: overall, 1,068; diabetes, 313; and pre-diabetes, 719 .

$\mathrm{SE}$, standard error; LVH, left ventricular hypertrophy; HbA1c, glycated hemoglobin; BMl, body mass index; NA, not applicable.

1.00 [tertile 2 vs. 1 ] and $\Delta=2.24$ [tertile 3 vs. 1 ]; $P=0.010$ ) among subjects with pre-diabetes in comparison to those without these coexisting CV risk factors (Supplementary Table 2).

Multivariate analysis that included factors with statistical significance $(P<0.005)$ in the univariate analysis was performed to iden-
Table 3. Framingham risk score according to $\mathrm{HbA} 1 \mathrm{c}$

\begin{tabular}{lcccc}
\hline Variable & $\mathrm{n}^{*}$ & $\begin{array}{c}\text { Parameter } \\
\text { estimate }\end{array}$ & $\begin{array}{c}\text { Standard } \\
\text { error }\end{array}$ & $P$ \\
\hline Total & 980 & & & \\
Overall HbA1c & & 2.41 & 0.26 & $<0.001$ \\
HbA1c $(\%)^{\dagger}$ & & & & \\
$\geq 5$ to $<6$ & 367 & 1.47 & 5.96 & 0.806 \\
$\geq 6$ to $<6.5$ & 322 & 5.03 & 5.96 & 0.398 \\
$\geq 6.5$ to $<7$ & 125 & 7.07 & 5.99 & 0.238 \\
$\geq 7$ & 164 & 10.14 & 5.98 & 0.090 \\
\hline
\end{tabular}

*The number of subjects included in the analysis; ${ }^{\dagger}$ Analysis for the relationship between $\mathrm{HbA1C}$ and FRS (linear regression analysis); ${ }^{\ddagger}$ Analysis for the relationship between HbA1c classification and FRS (linear regression analysis).

HbA1c, glycated hemoglobin; FRS, Framingham risk score.

tify significant $\mathrm{CV}$ risk factors (Table 2). FRS was elevated in diabetic subjects $(\mathrm{n}=199)$ who consumed alcohol $(2.66, P=0.033)$ and fell in the obesity-class II category $(6.10, P=0.015)$ while it was elevated in pre-diabetic subjects $(\mathrm{n}=306)$ with LVH $(11.10$, $P=0.005)$, alcohol consumption $(3.06, P<0.001)$, pre-obesity (3.21, $P=0.002)$, and obesity-class I $(2.89, P=0.002)$ in comparison to subjects without these coexisting risk factors (Table 2).

\section{HbAlc, insulin usage, and association with FRS and CV risk}

Overall, the mean \pm SD HbAlc was $6.34 \% \pm 1.03 \%(\mathrm{n}=1,154)$; $\mathrm{HbAlc}$ was $8.29 \% \pm 2.06 \%$ in insulin users $(\mathrm{n}=18)$ and $6.30 \% \pm$ $0.98 \%$ in non-insulin users $(\mathrm{n}=1,136)$, and a significant increase in FRS was noted with an increase in HbAlc $(2.41, P<0.001)$. Further, with each $0.5 \%$ to $1 \%$ increase in $\mathrm{HbAlc}$ from $5 \%$ to $7 \%$, there was a directly proportional but statistically insignificant increase in the FRS (Table 3). HbAlc $\geq 7 \%$ was associated with a higher CV risk than an $\mathrm{HbAlc}<7 \%$ (odds ratio, 3.43; $P=0.026$ ). Insulin usage, however, did not have a statistically significant association with the FRS. An increase in BMI tended to be associated with an increase in FRS. In particular, a J-shaped curve was observed in men with diabetes as the FRS was high for those men with a BMI $<18.5 \mathrm{~kg} / \mathrm{m}^{2}$ (Fig. 3).

\section{DISCUSSION}

In this study, about $33 \%$ of subjects had diabetes, while the remaining subjects had pre-diabetes. Evaluation of $\mathrm{CV}$ risk using the 


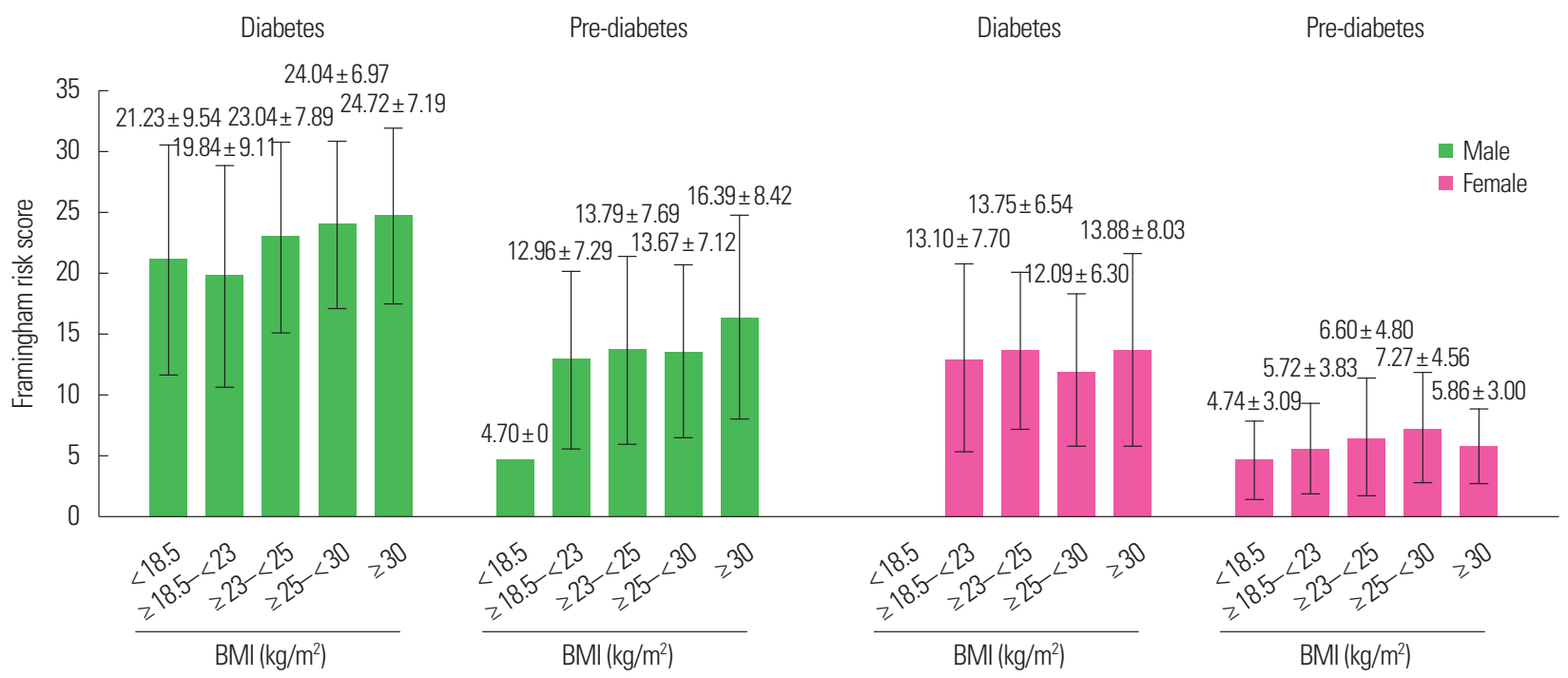

Figure 3. Comparison of Framingham risk score according to body mass index (BMI). Values are presented as mean \pm standard deviation.

FRS indicated that CV risk was significantly higher in subjects with diabetes than in those with pre-diabetes. When stratified by sex, men were at a higher CV risk than women, and men with pre-diabetes had a similar CV risk to that of women with diabetes. In addition, alcohol consumption and obesity were the most significant predictors of CV risk in Koreans with diabetes, while LVH, preobesity, and obesity were the most significant predictors of $\mathrm{CV}$ risk in Koreans with pre-diabetes.

The FRS estimation used in this study has been traditionally used to predict the 10 -year risk of coronary heart disease $(\mathrm{CHD})$ by factoring in age, smoking status, lipid profile, blood pressure, and presence or absence of diabetes. ${ }^{20,21}$ A survey based on data obtained from the third Korea National Health and Nutrition Examination in 2005 of 5,271 non-institutionalized civilians (aged 20-79 years) in the Republic of Korea revealed that the FRS was closely associated with prediction of $\mathrm{CHD}{ }^{22}$ In the current study, the mean FRS of 13.72 in subjects with pre-diabetes and diabetes indicates intermediate risk of developing CVD including stroke, peripheral artery disease, heart failure, and ischemic heart disease within 10 years. In a 10-year follow-up study of 2,775 subjects at high risk of diabetes, the mean Framingham 10-year CV risk scores were the highest in subjects with pre-diabetes (16.2\%), intermediate in subjects with normal glucose regulation (15.5\%), and the lowest in subjects with diabetes $(14.4 \%)\left(P<0.05\right.$ for all pairwise comparisons). ${ }^{23}$ In contrast, the present study established that the FRS was higher in sub- jects with diabetes than in those with pre-diabetes.

Various studies have been conducted to assess the impact of sex on diabetes-associated CV risk. ${ }^{24-26}$ In a cohort of 1,378 subjects selected from the Maracaibo City Metabolic Syndrome Prevalence Study, significantly higher coronary risk was observed in men with normoglycemia (3.28\%) than women with normoglycemia (2.05\%) $(P<0.001)$ and in men with IFG $(4.90 \%)$ than women with IFG $(2.75 \%)(P<0.001)$. Although the overall risk was greater in subjects with diabetes than in subjects with normoglycemia or IFG, no sex differences were evident. ${ }^{24} \mathrm{~A}$ meta analysis of 37 prospective cohort studies of T2DM and fatal CHD among 447,064 subjects revealed that the relative risk for fatal $\mathrm{CHD}$ associated with diabetes was $50 \%$ greater in women than in men. ${ }^{26}$ However, in the present study, the FRS in men was higher than that in women in both pre-diabetes and diabetes groups, indicating a clear sex difference. Men with pre-diabetes had a CV risk similar to women with diabetes. This finding highlights the need to create awareness that men with pre-diabetes are at greater risk of developing CV complications than women with pre-diabetes.

$\mathrm{CV}$ risk factors including obesity, hypertension, and dyslipidemia are common among subjects with diabetes, increasing the risk for $\mathrm{CV}$ events. It is therefore important to target $\mathrm{CV}$ risk factors in subjects with diabetes to minimize long-term CV complications associated with diabetes. ${ }^{27}$ We found that the mean FRS was notably higher in subjects with high CV risk than in subjects without high 
$\mathrm{CV}$ risk $(P=0.048)$ and confirmed that alcohol consumption (increased FRS by 2.66; standard error, 1.24; $P=0.033$ ) and obesityclass $\mathrm{II}^{28}$ (increased FRS by 6.10; standard error, 2.49; $P=0.015$ ) were significant contributors to $\mathrm{CV}$ risk in subjects with diabetes in Korea. In a study conducted in Taiwan that included 439 subjects with chronic kidney disease, presence of diabetes, coronary artery disease, low albumin, low hemoglobin, low estimated glomerular filtration rate, high uric acid, proteinuria, left atrial diameter $>4.7 \mathrm{~cm}$, $\mathrm{LVH}$, and left ventricular ejection fraction $<50 \%$ were all significantly associated with an increase in $\mathrm{CV}$ events. ${ }^{29} \mathrm{We}$ found that LVH $(P=0.005)$, alcohol consumption $(P=0.000)$, pre-obesity $(P=0.002)$, and obesity-class I $(P=0.002)$ were significantly associated with increased FRS in subjects with pre-diabetes in Korea. In contrast, various studies have shown that moderate alcohol consumption is associated with a reduced risk of incident diabetes. ${ }^{30,31}$ Obesity is a well-established risk factor for developing CV disease ${ }^{32}$ consistent with our findings in this study; both obesity and pre-obesity were significant contributors to increased $\mathrm{CV}$ risk in subjects with pre-diabetes or diabetes.

Association between $\mathrm{HbAlc}$ and $\mathrm{CV}$ risk and mortality has been extensively investigated. ${ }^{27} \mathrm{~A}$ systematic review (74 studies) and meta-analysis (46 studies) conducted by Cavero-Redondo et al. ${ }^{33}$ that included observational studies established that $\mathrm{HbAlc}$ had a positive association with all-cause mortality and $\mathrm{CV}$ mortality in both subjects with diabetes and those without diabetes. A study of 34,737 subjects with T2DM reported increased microvascular and macrovascular events in subjects with diabetes and $\mathrm{HbAlc}$ levels $\geq 6.5 \%$ as compared to subjects with $\mathrm{HbAlc}<6.5 \%$ for the 0 - to 1-year early exposure period. ${ }^{34} \mathrm{~A}$ retrospective study of 2,879 Korean adults aged 40 to 79 years without diabetes revealed that $\mathrm{HbAlc}$ levels were positively correlated with the FRS and may reflect CVD risk in subjects without diabetes. ${ }^{35}$ In the present study, we demonstrated that an increase in $\mathrm{HbAlc}$ was associated with an increase in the FRS, indicating a higher probability of CV complications in subjects with uncontrolled diabetes. In subjects with high CV risk, the FRS was higher when $\mathrm{HbAlc}$ was $\geq 7 \%$, alcohol was consumed, and $\mathrm{LVH}$ was present. $\mathrm{HbAlc} \geq 7 \%$ was associated with higher $\mathrm{CV}$ risk as compared to $\mathrm{HbAlc}<7 \%$, emphasizing the need for $\mathrm{HbAlc}$ control to prevent $\mathrm{CV}$ complications in subjects with pre-diabetes and diabetes in Korea.
Several meta-analyses of randomized controlled trials investigating the effects of intensive glycemic control on all-cause mortality, $\mathrm{CV}$ death, and vascular events in T2DM have shown limited benefits of therapy and no significant effects on CV outcomes. ${ }^{36-39}$ In this study, insulin usage did not significantly affect the FRS or high $\mathrm{CV}$ risk. However, the association between $\mathrm{HbAlc}$ and insulin usage and their cumulative effects on the FRS need to be further substantiated through future studies to assess the impact of insulin usage on the FRS and high CV risk.

BMI has been reported to be a strong predictor of future risk of $\mathrm{CHD} .{ }^{40}$ Positive, inverse, or U- and J-shaped associations between BMI and mortality among subjects with diabetes have been reported in different studies. ${ }^{41-44}$ Association between BMI and CHD risk among 30,434 low-income and underinsured subjects with diabetes in the United States was positive among both men and women with T2DM at baseline and during the more than 7 years of followup. ${ }^{45}$ The current study confirmed that CV risk increases with increasing $\mathrm{BMI}$ in subjects with diabetes, highlighting the importance of monitoring $\mathrm{BMI}$ to prevent $\mathrm{CHD}$ among subjects with diabetes.

\section{Limitations of the study}

This study assessed CV risk in subjects with pre-diabetes and diabetes based on their medical records, which is a limitation of this study, as the data may not be reliable if the required information was not noted correctly in the medical records. The period of the study over which the data were collected, i.e., 7 months may not be a representative of long-term trends. Because subjects with normal glucose levels were not included, the CV risk in subjects with prediabetes and diabetes could not be compared to that of non-diabetic subjects. Factors required for calculation of FRS included status of treatment with antihypertensive drugs. However, because antihypertensive treatment status was not available in 276 subjects, the FRS could not be calculated for these cases. However, an imputation method was used to account for subjects for whom antihypertensive treatment status was not available, and the mean \pm SD FRS calculated using for this dataset was similar to that of the group for which data were available. Furthermore, data on the use of antihyperlipidemic drugs were missing for 341 subjects and may have impacted the FRS results. Some of the missing data, such as that on 
alcohol consumption, could also have impacted the results. In addition, to determine high CV risk, previous MI, stroke, revascularization, and angina were assessed. Due to difficulty in elucidating the time sequences of these events in this cross-sectional study, we could not confidently assess correlations between the effects of current insulin use/status of $\mathrm{HbAlc}$ control and high CV risk. Furthermore, very few subjects were on insulin therapy. Family history of premature $\mathrm{CV}$ events is an important determinant of $\mathrm{CV}$ risk. ${ }^{46}$ However, data on the family history of premature $\mathrm{CV}$ events were not collected in this study; further studies are needed to determine if family history of premature CV events affects CV risk. Finally, some researchers have suggested that the FRS may not be suitable for some populations, including Koreans. ${ }^{47}$ Therefore, the results of this study should be verified using other CV risk scoring models. In conclusion, based on the overall distribution and characteristics of $\mathrm{CV}$ risk, Korean subjects with pre-diabetes and diabetes are at high risk for developing CVD, and subjects with diabetes have a significantly higher predisposition for developing CVD than those with pre-diabetes. Risk stratification based on sex, BMI, and underlying comorbidities can be used to develop measures to prevent and manage CV complications in Korean subjects with impaired glucose metabolism.

\section{CONFLICTS OF INTEREST}

Won Kim and Kyoung Hwa Lee are employees of Sanofi. No other potential conflicts of interest relevant to this article were reported.

\section{ACKNOWLEDGMENTS}

This study was funded by Sanofi-Aventis Korea, Ltd. Editorial support in the preparation of this publication was provided by APCER Life Sciences and was paid for by Sanofi, India. Editorial support was also provided by Anahita Gouri and Rohan Mitra of Sanofi, India. The authors individually and collectively are responsible for all content and editorial decisions and have received no payment from Sanofi, directly or indirectly (through a third party), for the development/presentation of this publication.

\section{AUTHOR CONTRIBUTIONS}

Study concept and design: HSK, KHS, ISN, and TSP; acquisition of data: HSK, KHS, ISN, TSP, JMY, DSK, HSS, KJA, SHC, and SHK; analysis or interpretation of data: HSK, WK, and KHL; drafting of the manuscript: HSK, KHS, and WK; critical revision of the manuscript: HSK and WK; and study supervision: ISN and TSP.

\section{REFERENCES}

1. International Diabetes Federation. IDF diabetes atlas 9th edition [Internet]. Brussels: International Diabetes Federation; 2020 [cited 2021 Jul 30]. Available from: https://www.diabetesatlas.org/en/resources/

2. Korean Diabetes Association. Diabetes fact sheet in Korea: 2018 [Internet]. Seoul: Korean Diabetes Association; 2020 [cited $2021 \mathrm{Jul}$ 30]. Available from: http://www.diabetes.or. $\mathrm{kr} / \mathrm{bbs} /$ index.html?code $=\mathrm{e} \_$resource $\&$ mode $=$ tlist

3. Kolb H, Martin S. Environmental/lifestyle factors in the pathogenesis and prevention of type 2 diabetes. BMC Med 2017; 15:131.

4. Lawes CM, Parag V, Bennett DA, Suh I, Lam TH, Whitlock G, et al. Blood glucose and risk of cardiovascular disease in the Asia Pacific region. Diabetes Care 2004;27:2836-42.

5. DECODE Study Group; the European Diabetes Epidemiology Group. Glucose tolerance and cardiovascular mortality: comparison of fasting and 2-hour diagnostic criteria. Arch Intern Med 2001;161:397-405.

6. Balkau B, Shipley M, Jarrett RJ, Pyörälä K, Pyörälä M, Forhan A, et al. High blood glucose concentration is a risk factor for mortality in middle-aged nondiabetic men: 20-year follow-up in the Whitehall study, the Paris prospective study, and the Helsinki policemen study. Diabetes Care 1998;21:360-7.

7. Huang Y, Cai X, Mai W, Li M, Hu Y. Association between prediabetes and risk of cardiovascular disease and all cause mortality: systematic review and meta-analysis. BMJ 2016; 355:i5953.

8. Davies MJ, D'Alessio DA, Fradkin J, Kernan WN, Mathieu C, Mingrone G, et al. Management of hyperglycemia in type 2 diabetes, 2018: a consensus report by the American Diabetes 
Association (ADA) and the European Association for the Study of Diabetes (EASD). Diabetes Care 2018;41:2669-701.

9. Korean Diabetes Association. Treatment guidelines for diabetes. 5th ed. [Internet]. Seoul: Korean Diabetes Association; 2015 [cited 2021 Jul 30]. Available from: http://www.diabetes.or.kr $/ \mathrm{bbs} /$ index.html? code $=$ e_resource $\&$ mode $=$ tlist

10. Kariuki JK, Stuart-Shor EM, Leveille SG, Hayman LL. Evaluation of the performance of existing non-laboratory based cardiovascular risk assessment algorithms. BMC Cardiovasc Disord 2013;13:123.

11. Chamnan P, Simmons RK, Sharp SJ, Griffin SJ, Wareham NJ. Cardiovascular risk assessment scores for people with diabetes: a systematic review. Diabetologia 2009;52:2001-14.

12. Stevens RJ, Coleman RL, Holman RR. Framingham risk equations underestimate coronary heart disease risk in diabetes. Diabet Med 2005;22:228.

13. Yeo WW, Yeo KR. Predicting CHD risk in patients with diabetes mellitus. Diabet Med 2001;18:341-4.

14. Garg N, Muduli SK, Kapoor A, Tewari S, Kumar S, Khanna R, et al. Comparison of different cardiovascular risk score calculators for cardiovascular risk prediction and guideline recommended statin uses. Indian Heart J 2017;69:458-63.

15. Eichler K, Puhan MA, Steurer J, Bachmann LM. Prediction of first coronary events with the Framingham score: a systematic review. Am Heart J 2007;153:722-31, e1-8.

16. Andrews EA, Avorn J, Bortnichak EA, Chen R, Dai WS, Dieck GS, et al. Guidelines for good epidemiology practices for drug, device, and vaccine research in the United States. Pharmacoepidemiol Drug Saf 1996;5:333-8.

17. American Diabetes Association. 10. Cardiovascular disease and risk management: standards of medical care in diabetes2019. Diabetes Care 2019;42(Suppl 1):S103-23.

18. Kim MK, Ko SH, Kim BY, Kang ES, Noh J, Kim SK, et al. 2019 Clinical practice guidelines for type 2 diabetes mellitus in Korea. Diabetes Metab J 2019;43:398-406.

19. American Diabetes Association. Standards of medical care in diabetes: 2013. Diabetes Care 2013;36 Suppl 1(Suppl 1): S11-66.

20. Grundy SM, Balady GJ, Criqui MH, Fletcher G, Greenland P, Hiratzka LF, et al. Primary prevention of coronary heart dis- ease: guidance from Framingham: a statement for healthcare professionals from the AHA Task Force on Risk Reduction. American Heart Association. Circulation 1998;97:1876-87.

21. Khanna R, Kapoor A, Kumar S, Tewari S, Garg N, Goel PK. Metabolic syndrome \& Framingham risk score: observations from a coronary angiographic study in Indian patients. Indian J Med Res 2013;137:295-301.

22. Kang HM, Kim DJ. Metabolic Syndrome versus Framingham Risk Score for Association of Self-Reported Coronary Heart Disease: The 2005 Korean Health and Nutrition Examination Survey. Diabetes Metab J 2012;36:237-44.

23. Perreault L, Temprosa M, Mather KJ, Horton E, Kitabchi A, Larkin M, et al. Regression from prediabetes to normal glucose regulation is associated with reduction in cardiovascular risk: results from the Diabetes Prevention Program outcomes study. Diabetes Care 2014;37:2622-31.

24. Bermúdez V, Rojas J, Salazar J, Gonzalez R, Martinez MS, Chavez $\mathrm{C}$, et al. Coronary risk estimation according to the Framingham-Wilson score and impaired fasting glucose in adult subjects from Maracaibo city, Venezuela. Glob J Obes Diabetes Metab Syndr 2014;1:20-9.

25. Ford ES, Zhao G, Li C. Pre-diabetes and the risk for cardiovascular disease: a systematic review of the evidence. J Am Coll Cardiol 2010;55:1310-7.

26. Huxley R, Barzi F, Woodward M. Excess risk of fatal coronary heart disease associated with diabetes in men and women: meta-analysis of 37 prospective cohort studies. BMJ 2006; 332:73-8.

27. Leon BM, Maddox TM. Diabetes and cardiovascular disease: epidemiology, biological mechanisms, treatment recommendations and future research. World J Diabetes 2015;6:1246-58.

28. Seo MH, Lee WY, Kim SS, Kang JH, Kang JH, Kim KK, et al. 2018 Korean Society for the Study of Obesity guideline for the management of obesity in Korea. J Obes Metab Syndr 2019;28:40-5.

29. Chen SC, Su HM, Tsai YC, Huang JC, Chang JM, Hwang SJ, et al. Framingham risk score with cardiovascular events in chronic kidney disease. PLoS One 2013;8:e60008.

30. Polsky S, Akturk HK. Alcohol consumption, diabetes risk, and cardiovascular disease within diabetes. Curr Diab Rep 
2017;17:136.

31. Crandall JP, Polsky S, Howard AA, Perreault L, Bray GA, Barrett-Connor E, et al. Alcohol consumption and diabetes risk in the Diabetes Prevention Program. Am J Clin Nutr 2009;90:595-601.

32. Yoo B, Nam H, Hwang IC, Park Y. Correlation of cardiovascular risk factors with central obesity and multiple body mass index in Korea. Korean J Fam Med 2017;38:338-45.

33. Cavero-Redondo I, Peleteiro B, Álvarez-Bueno C, RodriguezArtalejo F, Martínez-Vizcaíno V. Glycated haemoglobin A1c as a risk factor of cardiovascular outcomes and all-cause mortality in diabetic and non-diabetic populations: a systematic review and meta-analysis. BMJ Open 2017;7:e015949.

34. Laiteerapong N, Ham SA, Gao Y, Moffet HH, Liu JY, Huang ES, et al. The legacy effect in type 2 diabetes: impact of early glycemic control on future complications (the diabetes \& aging study). Diabetes Care 2019;42:416-26.

35. Shin JH, Kang JI, Jung Y, Choi YM, Park HJ, So JH, et al. Hemoglobin Alc is positively correlated with Framingham risk score in older, apparently healthy nondiabetic Korean adults. Endocrinol Metab (Seoul) 2013;28:103-9.

36. Boussageon R, Bejan-Angoulvant T, Saadatian-Elahi M, Lafont S, Bergeonneau C, Kassaï B, et al. Effect of intensive glucose lowering treatment on all cause mortality, cardiovascular death, and microvascular events in type 2 diabetes: meta-analysis of randomised controlled trials. BMJ 2011;343:d4169.

37. Ray KK, Seshasai SR, Wijesuriya S, Sivakumaran R, Nethercott S, Preiss D, et al. Effect of intensive control of glucose on cardiovascular outcomes and death in patients with diabetes mellitus: a meta-analysis of randomised controlled trials. Lancet 2009;373:1765-72.

38. Control Group, Turnbull FM, Abraira C, Anderson RJ, Byington RP, Chalmers JP, et al. Intensive glucose control and macrovascular outcomes in type 2 diabetes. Diabetologia 2009;52:2288-98.

39. Hemmingsen B, Lund SS, Gluud C, Vaag A, Almdal T, Hem- mingsen $\mathrm{C}$, et al. Intensive glycaemic control for patients with type 2 diabetes: systematic review with meta-analysis and trial sequential analysis of randomised clinical trials. BMJ 2011; 343:d6898.

40. Flint AJ, Rexrode KM, Hu FB, Glynn RJ, Caspard H, Manson JE, et al. Body mass index, waist circumference, and risk of coronary heart disease: a prospective study among men and women. Obes Res Clin Pract 2010;4:e171-81.

41. Bhaskaran K, Dos-Santos-Silva I, Leon DA, Douglas IJ, Smeeth L. Association of BMI with overall and cause-specific mortality: a population-based cohort study of 3.6 million adults in the UK. Lancet Diabetes Endocrinol 2018;6:944-53.

42. Kokkinos P, Myers J, Faselis C, Doumas M, Kheirbek R, Nylen E. BMI-mortality paradox and fitness in African American and Caucasian men with type 2 diabetes. Diabetes Care 2012; $35: 1021-7$.

43. Chen Y, Copeland WK, Vedanthan R, Grant E, Lee JE, Gu D, et al. Association between body mass index and cardiovascular disease mortality in east Asians and south Asians: pooled analysis of prospective data from the Asia Cohort Consortium. BMJ 2013;347:f5446.

44. Tobias DK, Pan A, Jackson CL, O’Reilly EJ, Ding EL, Willett WC, et al. Body-mass index and mortality among adults with incident type 2 diabetes. N Engl J Med 2014;370:233-44.

45. Li N, Katzmarzyk PT, Horswell R, Zhang Y, Li W, Zhao W, et al. BMI and coronary heart disease risk among low-income and underinsured diabetic patients. Diabetes Care 2014;37: 3204-12.

46. Mulders TA, Meyer Z, van der Donk C, Kroon AA, Ferreira I, Stehouwer CD, et al. Patients with premature cardiovascular disease and a positive family history for cardiovascular disease are prone to recurrent events. Int J Cardiol 2011;153:64-7.

47. Jee SH, Jang Y, Oh DJ, Oh BH, Lee SH, Park SW, et al. A coronary heart disease prediction model: the Korean Heart Study. BMJ Open 2014;4:e005025. 